\title{
THE ACETABULAR NOTCH IN HIP DYSPLASIA
}

\author{
N. M. A. PORTINARO, S. J. E. MATTHEWS, M. K. D. BENSON
}

From the Nuffield Orthopaedic Centre, Oxford, England

In the first few months of life, a notch may be seen on radiographs of the superolateral margin of the infant hip. It may be associated with a steeply inclined acetabular roof and may be an indicator of persistent neonatal instability or displacement of the femoral head.

J Bone Joint Surg [Br] 1994; 76-B:271-3.

Received 9 August 1993; Accepted 15 September 1993

The human hip develops from a lateral mesenchymal bud. The cleft in the primordial hip cartilage which, in the 8 -week/30 mm fetus heralds the development of the hip, was described by Gardner and Gray (1950) and Strayer (1971). In the 11 -week $/ 50 \mathrm{~mm}$ fetus the joint cavity develops after the breakdown of a layer of less dense cartilage cells, perhaps because of mechanical stress (muscular activity) or a local degenerative process (Watanabe 1974). It is at this period of gestation that the acetabular socket is at its deepest relative to the femoral head (Ippolito, Tovaglia and Caterini 1984).

The peripheral nervous system develops in a cephalocaudal direction and is completely formed before active muscular contraction begins. In the lower limbs, active hip flexion and adduction (iliopsoas) are followed by knee extension (quadriceps), knee flexion (femoral biceps) and later by foot movements (Weiss 1939).

Watanabe (1974) suggested that the hip may first be dislocatable in the 11-week-old fetus because by then the joint cavity has formed and the hip flexors have become active.

Appositional growth and remodelling allow the capacity, diameter and depth of the acetabulum to increase reciprocally with the enlarging and maturing femoral head (Harrison 1961; Plaster, Schoenecker and Capelli 1991). Growth of the acetabulum in fetal and postnatal life occurs predominantly at the triradiate cartilage. This

N. M. A. Portinaro, MD, Research Fellow Department of Orthopaedic Surgery, San Raffaele Hospital, University of Milan, Via Olgettina 60, Milan, Italy.

S. J. E. Matthews, FRCS, Senior Registrar

M. K. D. Benson, FRCS, Consultant Orthopaedic Surgeon

Nuffield Department of Orthopaedic Surgery, Nuffield Orthopaedic Centre NHS Trust, Windmill Road, Headington, Oxford OX3 7LD, UK.

Correspondence should be sent to Mr M. K. D. Benson.

C1994 British Editorial Society of Bone and Joint Surgery 0301-620X/94/2751 \$2.00 expanding structure consists of three growth plates at the junctions of the ilium, ischium and pubis, which fuse completely between the ages of 12 and 14 years (O'Hara 1989). The lateral acetabular ring epiphysis contributes to peripheral acetabular growth, thereby increasing its depth. Ossification of the ring epiphysis begins at nine years and by 18 years the ring epiphyseal ossific nucleus has usually fused to the ilium (Ponseti 1978). The capacity for the acetabulum to enlarge laterally ceases when the ring epiphysis has completely ossified.

Perinatally, the altered hormonal environment of the mother and infant allows laxity of both maternal and infant ligamentous and capsular tissues (Andren and Borglin 1961; Theime and Wynne-Davies 1968). At the end of normal gestation, the containment of the femoral head by the acetabulum is less than at any other stage of fetal development (Morville 1949; McKibbin 1970; Ralis and McKibbin 1973). In these physiological but unfavourable conditions, the hip is vulnerable to displacement or dislocation when placed in a less than ideal position, such as extended breech.

Laurenson (1965) has shown by anatomical dissection that the proportion of cartilage to bone in the ring epiphysis is greater when instability or subluxation is present. Eccentric pressure on the ring epiphysis allows its distortion and delays ossification of the roof of the acetabulum (Ponseti 1978).

\section{THE ACETABULAR NOTCH}

We have observed the radiological appearance of a notch at the superolateral margin of the acetabulum in hips referred for neonatal instability or presenting later with subluxation (Fig. 1). A 'fossa' (Doberti and Manhood 1968) or 'groove' (Garavaglia 1970) has previously been described but no convincing explanation for its development has been advanced.

We have studied the appearance of this notch by sequential neonatal ultrasonography and later by radiography. On ultrasound it appears as a cup-shaped defect in the lateral iliac wall immediately above the acetabulum. The floor of the small crater is demonstrated by a concave, highly echogenic sclerotic line. Ultrasonographically, the defect has the characteristics of non-ossified hyaline cartilage with a diameter which is consistently 3 to $5 \mathrm{~mm}$ (Fig. 2).

The notch was studied in a pilot group of 170 hips referred to our ultrasound clinic with neonatal hip 


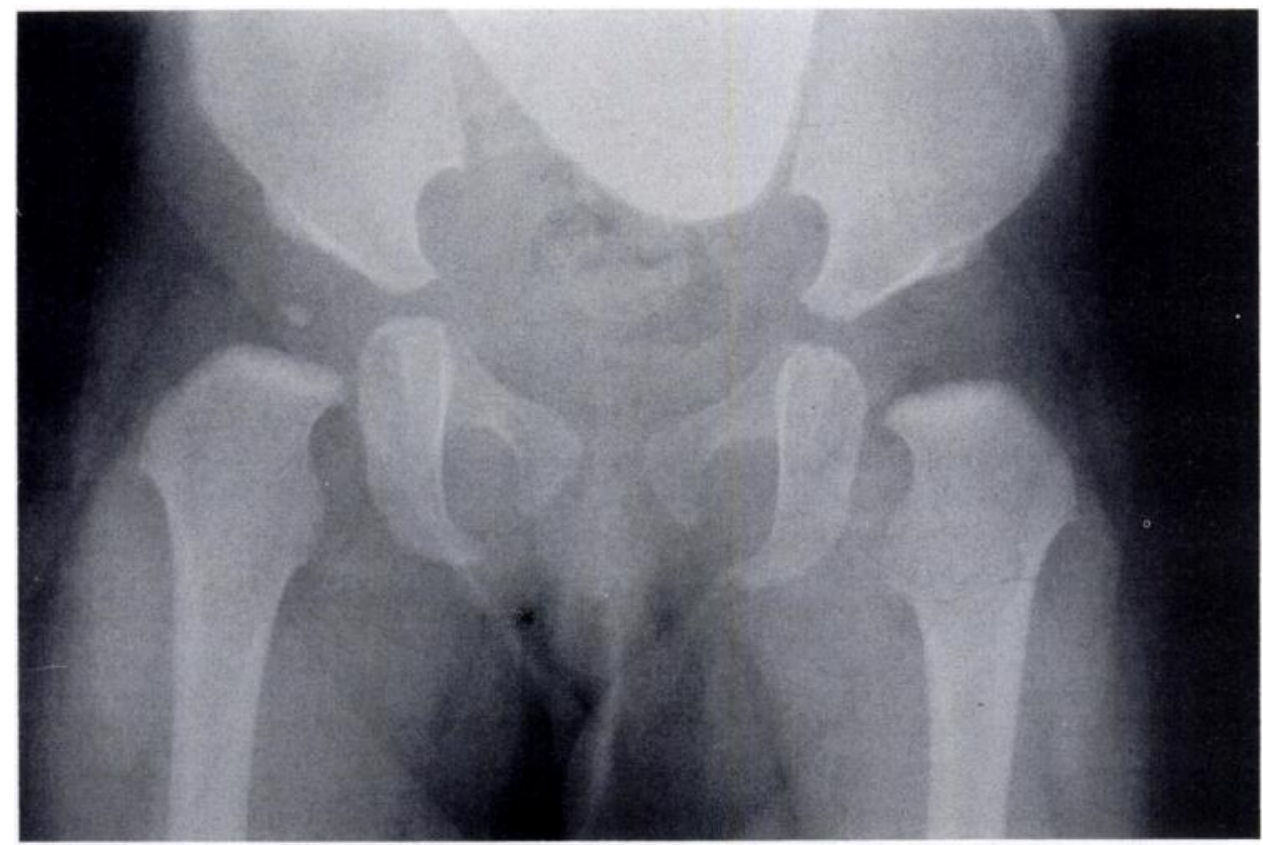

Fig. 1

Radiological appearance of bilateral acetabular notch. The defects on the superolateral aspect of the acetabulum are demarcated medially by a line of sclerotic bone.

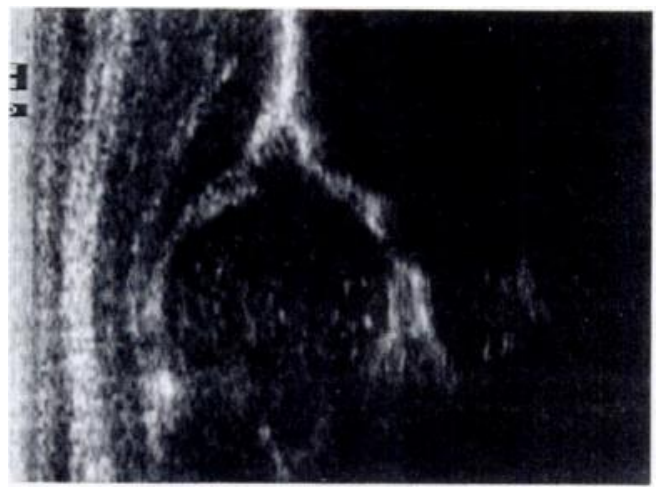

Fig. 2a

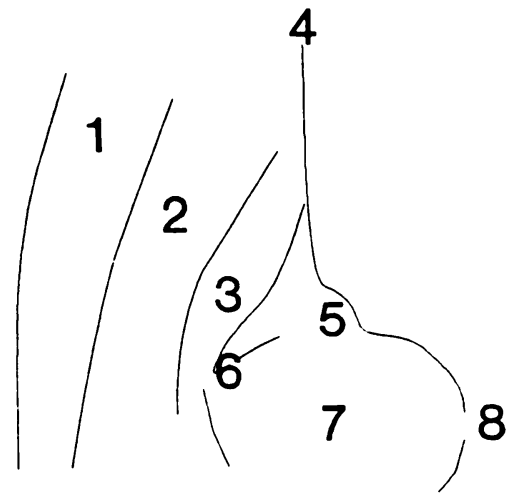

Fig. 2b
1. Gluteus maximus

2. Gluteus medius

3. Gluteus minimus

4. Outer table ilium

5. Acetabular notch

6. Labrum

7. Femoral head

8. Triradiate cartilage

Ultrasonogram (a) and diagram (b) showing the acetabular notch as a cup-shaped defect in the lateral iliac wall. Its medial border is defined by a concave, highly echogenic, sclerotic line.

instability, breech presentation, a positive family history or an associated skeletal anomaly. It was found in $5 \%$ of the hips that were otherwise ultrasonographically normal and in 54\% of those which were either shallow or unstable.

Radiographically, it appears as a punched-out defect on the superolateral aspect of the ilium where the acetabular roof joins the iliac wing. It is concave and elliptical in shape with a diameter of 4 to $8 \mathrm{~mm}$. Its floor is demarcated by a line of sclerotic bone. It is associated with a steep, deformed acetabular roof and often with clinically detectable instability of the hip.

\section{DISCUSSION}

Copray, Jansen and Duterloo (1985) showed that physiological load stimulates the cellular proliferation of cartilage and the synthesis of matrix proteins at the epiphysealmetaphyseal junction. Klein-Nulend, Veldhuijzen and Burger (1986) further demonstrated that calcium and phosphate deposition increases in the hypertrophic layer of the growth plate when it is stimulated by intermittent axial compressive loads. Chondrocytes in culture are stimulated by intermittent multidirectional compression, the mitotic index decreases and the intracellular fibrotic matrix increases (van Kampen et al 1985).

Salter and Harris (1963) and Lorini, Specchia and Greco (1992) showed that a single large compression load on a growth plate results in a decrease in cellular activity and delayed growth, leading even to temporary or permanent epiphysiodesis; by contrast, prolonged compression with a minimal load stimulates cellular proliferation and matrix component synthesis. If load on the 
growth plate is axial, there is an increase in protein synthesis with adhesion of proteoglycan and an increase in calcium-phosphate deposition in the cartilaginous matrix. This process seems to occur in the proliferative layer. A decrease in the mitotic rate and an increase in the production of collagen are observed in the proliferative layer if the load is tangential, multidirectional or excessive.

Similar histomorphological changes have been well documented by Ponseti (1978) in congenitally dislocated hips in which there is a loss of proteoglycans and an increase in collagen deposition in the lateral acetabular roof. In displaced hips, the growth of the lateral acetabular epiphysis changes: the cartilage mutates histochemically from hyaline to fibrous, reducing its content of proteoglycans (Ippolito et al 1984). Irregular bone spicules penetrate the dysmorphic cartilage columns of the growth plate and may well represent the previously described partial epiphysiodesis. Normal ossification is commonly delayed (Ponseti 1978).

It is this change in the quality of the acetabular epiphyseal cartilage that explains many debates about the

\section{REFERENCES}

Andren L, Borglin NE. Disturbed urinary excretion pattern of oestrogens in newborns with congenital dislocation of the hip. I. Acta Endocr $1961 ; 37: 423-6$.

Copray JC, Jansen HW, Duterloo HS. An in vitro system for studying the effect of variable compressive forces on the mandibular condylar cartilage of the rat. Arch Oral Biol 1985; 30:305-11.

Doberti A, Manhood J. A new radiological sign for early diagnosis of congenital hip dysplasia. Ann Radiol Paris 1968; II:276-81.

Garavaglia C. Early diagnosis of congenital dysplasia of the hip: new roentgenologic signs. Am J Roentgenol Radium Ther Nucl Med 1970; 110:587-90.

Gardner E, Gray DJ. Prenatal development of the human hip joint. Am J Anat 1950; 87:163-211.

Gibson P, Benson MKD. Congenital dislocation of the hip: review at maturity of 147 hips treated by excision of the limbus and derotation osteotomy. J Bone Joint Surg [Br] 1982; 4-13:169-75.

Harrison TJ. Influence of the femoral head on pelvic growth and acetabular form in the rat. J Anat 1961; 95:12-24.

Ippolito E, Tovaglia V, Caterini R. Mechanisms of acetabular growth in the fetus in relation to the pathogenesis and treatment of congenital dislocation of the hip. Ital J Orthop Traumatol 1984; 10:501-10.

van Kampen GP, Veldhuijzen JP, Kuijer R, van de Stadt $R$ J, Schipper CA. Cartilage response to mechanical force in high-density chondrocyte cultures. Arthritis Rheum 1985; 28:419-24.

KJein-Nulend J, Veldhuijzen JP, Burger EH. Increased calcification of growth-plate cartilage as a result of compressive force in vitro. Arthritis Rheum 1986; 29:1002-9.

Laurenson RD. Development of the acetabular roof in the fetal hip: an arthrographic and histological study. J Bone Joint Surg [Am] 1965; 47-A:975-83. 'limbus'. When excised surgically at open reduction and examined histologically, it often appears as fibrocartilage. Poor subsequent development of the acetabular rim is often seen in later radiographs and confirms that, in part, the ring epiphyseal cartilage has been excised with it (Gibson and Benson 1982).

There is good experimental evidence, therefore, to suggest a mechanism for the development of acetabular dysplasia and the formation of the radiological notch. We hypothesise that either constitutional ligamentous laxity or malpositioning in utero leads to eccentric loading of the ring epiphysis. This allows the femoral head to displace further and encourages progressive deformity and diminished growth of the ring epiphysis. Temporary growth arrest in the acetabular notch may be seen either ultrasonographically or radiologically. The deformed ring epiphysis may dedifferentiate in part from hyaline to fibrous cartilage and its inappropriate excision may lead to defective acetabular marginal growth.

No benefits in any form have been received or will be received from a commercial party related directly or indirectly to the subject of this article.

Lorini G, Specchia N, Greco F. Caratteristiche della cartilagine di accrescimento. In: Il punto su la patologia della cartilagine di accrescimento e il rimodellamento osseo. Firenze: OIC Medical Press, 1992.

McKibbin B. Anatomical factors in the stability of the hip joint in the newborn. J Bone Joint Surg [Br] 1970; 52-B:149-59.

Morville P. On the anatomy and pathology of the hip joint. Acta Orthop $1949 ; 7: 8-142$.

O'Hara JN. Congenital dislocation of the hip: acetabular deficiency in adolescence (absence of the lateral acetabular epiphysis) after limbectomy in infancy. J Pediatr Orthop 1989; 9:640-8.

Plaster RL, Schoenecker PL, Capelli AM. Premature closure of the triradiate cartilage: a potential complication of pericapsular acetabuloplasty. J Pediatr Orthop 1991; 11:676-8.

Ponseti IV. Morphology of the acetabulum in congenital dislocation of the hip: gross, histological and roentgenographic studies. J Bone Join Surg [Am] 1978; 60-A:586-99.

Ralis ZA, McKibbin B. Changes in shape of the human hip joint during its development and their relationship to its stability. $J$ Bone Joint Surg [Br] 1973; 55-B:780-5.

Salter RB, Harris R. Injuries involving the epiphyseal plate. $J$ Bone Joint Surg [Am] 1963; 45-A:587-622.

Strayer LM. Embryology of the human hip joint. Clin Orthop 1971 $74: 221-40$.

Theime WT, Wynne-Davies R. Clinical examination and urinary oestrogen assays in newborn children with congenital dislocation of the hip. J Bone Joint Surg [Br] 1968; 50-B:546-9.

Watanabe RS. Embryology of the human hip. Clin Orthop 1974; 98:8-26.

Weiss P. Principles of development. New York: Holt, 1939. 